\title{
Design para a educação: Projeto Uped! História, uma ferramenta de ensino para a disciplina de história no ensino médio da rede pública Design para a educação: Projeto Uped! História, uma ferramenta de ensino para a disciplina de história no ensino médio da rede pública
}

\author{
Maria Alice Coelho \& Patrícia Thormann
}

design para educação, design gráfico, design da Informação, história, educação

O artigo apresenta alguns aspectos explorados sobre a educação pública no ensino médio, contexto e problemas, conceitos do design para educação, design da informação e design instrucional, e o desenvolvimento do projeto que tem como objetivo de gerar novas ferramentas de que auxiliem no combate ao desinteresse dos alunos dentro da sala de aula. O projeto Uped!, foi desenvolvido através da sustentação em pesquisas de campo, análises de similares e a metodologia de Munari (1981) com apoio de ferramentas de arquitetura da informação, obtendo como resultado materiais impreso e digital para o ensino e aprendizagem, que proporcionem a interação entre alunos e professores e potencializem a capacidade de compreensão dos conteúdos de história do primeiro ano do ensino médio de escolas públicas.

design for education, graphic design, information design, history, education

The article presents some aspects explored about public education in high school, context and problems, concepts of design for education, information design and instructional design, and the development of the project that aims to generate new tools that help in the fight against students' lack of interest within the classroom. The Uped! Project was developed through the support of field research, similar analyzes and Munari's methodology (1981) with the support of information architecture tools, resulting in printed and digital materials for teaching and learning that provide the interaction between students and teachers and enhance the ability to understand the contents of history of the first year of high school public schools.

\section{Introdução}

A educação no ensino médio compreende jovens de 15 a 19 anos, e $84 \%$ dos matriculados dependem do ensino público (MEC, 2006). Segundo o IDEB, nos últimos anos a maior preocupação é com o aumento da taxa de desistência e reprovação.

A maioria dos alunos afirma ter dificuldade de memorizar as informações, prática comum nas escolas, o que prejudica o desempenho e interesse escolar, pois o desinteresse é diretamente ligado à dificuldade de aprendizagem e resultados negativos em disciplinas específicas (Krawczyk, 2009). Hoje existem diversos meios de ensino, mas também muitas barreiras para os alunos da rede pública.

O design pode proporcionar novos meios para auxiliar professores e alunos na busca por uma educação mais completa, principalmente através do design da informação, que segundo Fernandez Landreada (2004) proporciona a organização e estrutura dos conteúdos e não só o acesso a informação. Sendo ele então, o principal meio a ser explorado para o desenvolvimento deste projeto.

\section{A Educação}

De acordo com pesquisas, os principais motivos para a desistência ou infrequência escolar são problemas familiares, dificuldades em conciliar atividades escolares e trabalho, a desigualdade

Anais do 9 CIDI e 9 CONGIC

Luciane Maria Fadel, Carla Spinillo, Anderson Horta,

Cristina Portugal (orgs.)

Sociedade Brasileira de Design da Informação - SBD

Belo Horizonte | Brasil | 2019

ISBN 978-85-212-1728-2
Proceedings of the 9th CIDI and 9th CONGIC Luciane Maria Fadel, Carla Spinillo, Anderson Horta, Cristina Portugal (orgs.)

Sociedade Brasileira de Design da Informação - SBDI Belo Horizonte | Brazil | 2019

ISBN 978-85-212-1728-2 
social, fracasso anterior no ambiente escolar e falta de estímulo. (Costa Silveira; Tibiriça, 2010 como citado em Costa, Guimarães, Rocha, 2015)

Nemi (2009) afirma que não é de hoje que o ensino de História nas escolas é visto como matéria decorativa, porém o ensino de História não pode reduzir-se a memorização dos fatos, pois cabe à história dar uma perspectiva da evolução da humanidade com o objetivo de fazer os alunos compreenderem melhor o mundo presente (Moreira, 2001).

Sabe-se que a vivência destes jovens se dá num ambiente cercado pela tecnologia e redes de informação, e costuma-se dizer que os adolescentes têm grande facilidade para incorporar os novos recursos tecnológicos, mas isso não significa que o façam de forma crítica e produtiva. O desafio da escola não é protegê-los da tecnologia, mas prepará-los para usufruir dessa experiência. (Krawczyk, 2009, p. 26).

Vemos nos dias hoje, os acervos bibliográfico baseados em livros didáticos, poucas vezes outros tipos de materiais são mencionados como relevantes no acervo das escolas (Krawczyk, 2009, p.27), mas através do design podemos buscar respostas que contribuam para a mudança, não só da forma de apresentação, mas de interação com os conteúdos.

\section{Design}

O design propõe métodos de solucionar um problema, e esta solução tem como objetivo gerar melhoria na qualidade de vida do usuário (Munari, 1981), e quando aproximamos o design com a educação estamos arquitetando a construção de uma perspectiva social, centrada em princípios de design (gráfico e instrucional) que possam contribuir com as práticas educacionais (Coutinho, Lopes, 2011, p. 1).

O design instrucional tem como objetivo a ação intencional e sistemática de ensino que envolve processo de identificar um problema de aprendizagem, avaliar e implementar uma solução, a fim de promover a aprendizagem humana (Filatro, 2008, p.18), e colabora para a estruturação de novos meios de ensino. Hoje no meio digital a linguagem gráfica é utilizada constantemente, então o enfoque educacional deve equilibrar o seu desenvolvimento com as demais áreas, pois para que se forme um indivíduo capaz, é necessário que sua percepção de mundo esteja coerente com a realidade em que vive.

O design da Informação é área o design que trabalha a informação e linguagem gráfica, e tem como objetivo construir informações objetivas para alcançar resultados precisos, possuindo ferramentas para construir uma mensagem visual, de maneira que a torne compreensível, tanto do ponto de vista gráfico quanto informacional, de forma a otimizar a compreensão de significado (Martins, Couto, 2008). Devemos compreender então, que o design da informação assume nos dias de hoje um papel fundamental em qualquer projeto de design que visa facilitar a compreensão da informação (Silva, Cruz, Passos, 2012).

Para Horn (1998) a infografia é como um dos principais modelos da linguagem gráfica, como o tipo de discurso no qual se utiliza uma combinação de códigos icônicos e verbais para transmitir uma informação ampla e precisa, e acredita-se que este recurso pode ser benéfico quando aplicado em sala de aula, pois vai de encontro aos interesses e necessidades dos alunos, e poderá ser utilizado, na disciplina de História, tanto como um aporte inicial quanto como revisão de conteúdo (Junior, Lisboa, Coutinho, 2011, p. 7).

\section{Metodologia}

Para compreender o contexto do ensino médio da rede pública, foi realizada uma pesquisa de campo de caráter exploratório, através de um questionário digital e uma entrevista semi estruturada realizada em ambiente escolar com estudantes do ensino médio regular, EJA (educação para jovens e adultos) e seus professores. 
O projeto foi desenvolvido segundo a metodologia de Bruno Munari (1981), seguindo as etapas pertinentes ao contexto do projeto: definição do problema, Recolha de Dados, Análise de Dados, Criatividade, materiais e processos e solução.

Foram também incorporadas etapas de design instrucional, como a análise de fatores contextuais facilitadores e inibidores de aprendizagem e o mapeamento curricular, e arquitetura da informação, a organização, rotulação e navegação.

Após as análises das pesquisas de campo, através do olhar de design instrucional, destacou-se que todas as informações obtidas descrevem a luta entre contexto social e ambição educacional destes alunos, que buscam na escola um alento para melhorar a sua expectativa de vida. Levando a conclusão de que a construção de um material contextualizado com a realidade atual da informação, é uma oportunidade para auxiliar os alunos a mudarem o quadro de desinteresse escolar.

O desenvolvimento do projeto teve início com a exploração dos conceitos extraídos de mapas mentais, e paralelamente foram consideradas diversas soluções, tanto econômicas quanto funcionais, entre materiais impressos e digitais, que resultaram na escolha da infografia através de banners impressos com interação através do aplicativo, como forma de solução para o problema encontrado.

O mapeamento do conteúdo, seleção e organização, foi realizada com auxílio de uma professora que atua em escola pública, dando aula para os 3 anos do ensino médio e por isso tem conhecimento do cronograma e tempo que as escolas dispõe.

\section{Análises de similares}

Os infográficos selcionados, de revistas populares, foram analisados segundo os códigos visuais de João Gomes Filho (2003) (cromático, tipográfico, morfológico e tecnológico) e os aplicativos, gratuitos, segundo as heurísticas 1 (Visibilidade do status do sistema), 2 (Compatibilidade do sistema com o mundo real), 3 (Controle e liberdade do usuário), 4 (Consistência e padrões), 7 (Flexibilidade e eficiência de uso) e 8 (Estética e design minimalista) de Nielsen (1995), por corresponderem a critérios de usabilidade desejáveis a estes modelos de aplicativos.

Tanto infográficos quanto aplicativos foram analisados com o objetivo de obter inspiração e verificar pontos a serem melhorados, tendo como resultado as considerações do quadro 1.

Quadro1: Análise de similares.

\begin{tabular}{l|l|l} 
& Infográficos & Aplicativos \\
\hline Pontos positivos & $\begin{array}{l}\text { O material analisado possui uma } \\
\text { boa organização, hierarquização } \\
\text { e linguagem descomplicada, que } \\
\text { acompanhou claramente o } \\
\text { esquema de cores proposto e sua } \\
\text { intenção. Assim como } \\
\text { colaboraram para uma visão de } \\
\text { leitura de contéudos em blocos } \\
\text { com comunicação entre si. }\end{array}$ & $\begin{array}{l}\text { Todos os aplicativos utilizam uma } \\
\text { linguagem simplificada para } \\
\text { explicar os conteúdos, e tem uma } \\
\text { ordem cronológica a ser seguida. }\end{array}$ \\
\hline $\begin{array}{l}\text { Pontos a serem } \\
\text { melhorados }\end{array}$ & $\begin{array}{l}\text { Algumas informações ofereciam } \\
\text { mais de um fluxo de leitura, o que } \\
\text { poderia confundir os usuários em } \\
\text { alguns momentos. }\end{array}$ & $\begin{array}{l}\text { O único aplicativo que apresentou } \\
\text { uma forma mais visual do } \\
\text { contéudo, transformou-o uma } \\
\text { ferramenta mais complicada a } \\
\text { ponto de precisar de um tutorial } \\
\text { próprio. }\end{array}$ \\
\hline
\end{tabular}


Coelho, M.A. \& Thomazi, P.T. | Design para a educação: Projeto Uped! História, uma ferramenta de ensino para a disciplina de história no ensino médio da rede pública

\section{0 projeto}

Após todas as análises, os conceitos de educação e história foram explorados para uma melhor compreensão dos mesmos. Ambos foram decompostos através de mapas mentais que levaram a conclusão de que a história não é tratada como o elemento que é, uma construção, um movimento infinito e universal, como a educação, que é uma ferramenta de descoberta constante de novas possibilidades, ou seja, não existe um único resultado para a educação histórica, sua atualização é constante.

Esta definição resultou no termo upgrade educacional, (sigla Up+Ed), que descreve a construção e melhoria constante do saber, e representa o projeto de forma clara e objetiva.

O uso do material impresso unido ao material digital foi a forma encontrada para criar uma comunicação mais sutil entre a sala de aula e a tecnologia usada fora dela, pois a missão do Uped! História é, o upgrade educacional, através do uso da linguagem gráfica/visual, com foco para a disciplina de história do ensino médio público.

Os conteúdos selecionados para o desenvolvimento tiveram como objetivo manter o projeto mais próximo da realidade escolar, portanto foram baseados na Reestruturação curricular do RS (2016) e no material de aula de uma professora, docente de uma escola de ensino médio Estadual de Cachoeirinha, e do livro didático HISTÓRIA passado e presente volume 1 (2017), que após todo o processo foram então transferidos para a estrutura do material.

A decisão quanto ao formato dos materiais considerou que a tecnologia mobile é dominante entre os jovens entre 15 e 25 anos, e mesmo jovens de baixa renda têm acesso a celulares que suportam aplicativos básicos de forma eficiente. A comunicação entre os meios será através do QR code, código composto por caracteres codificados com uma alta capacidade de armazenamento dados.

Para viabilizar a produção dos banners a um custo acessível e padrão, as medidas foram definidas segundo padrão das gráficas, de $100 \times 80 \mathrm{~cm}$. Para a organização dos elementos e transmissão para o layout do aplicativo foi desenvolvido o grid, que possui 2 partes, cabeçalho e módulos de conteúdo. A composição a partir dos grids proporciona ao material impresso uma identidade, com diversas possibilidades de resultados.

Figura 1 - Cabeçalho padão para Banner (2018).

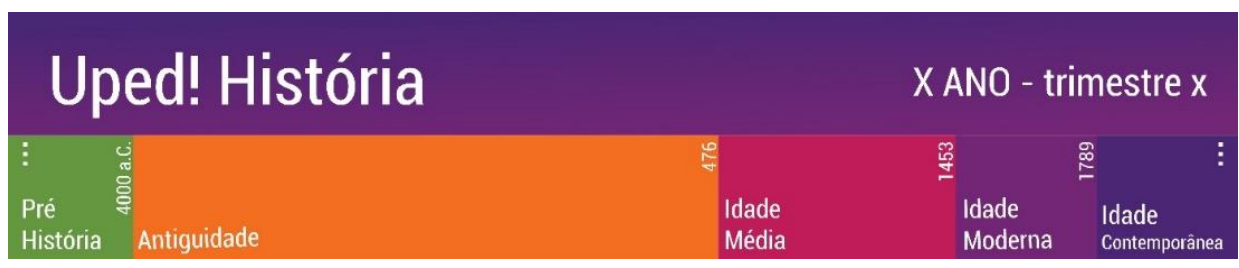

O conteúdo selecionado contempla 2 tempos históricos, respectivamente separados em 2 banners. 
Coelho, M.A. \& Thomazi, P.T. | Design para a educação: Projeto Uped! História, uma ferramenta de ensino para a disciplina de história no ensino médio da rede pública

Figura 2 - Resultado do Banner pré-história e antiguidade (2018).

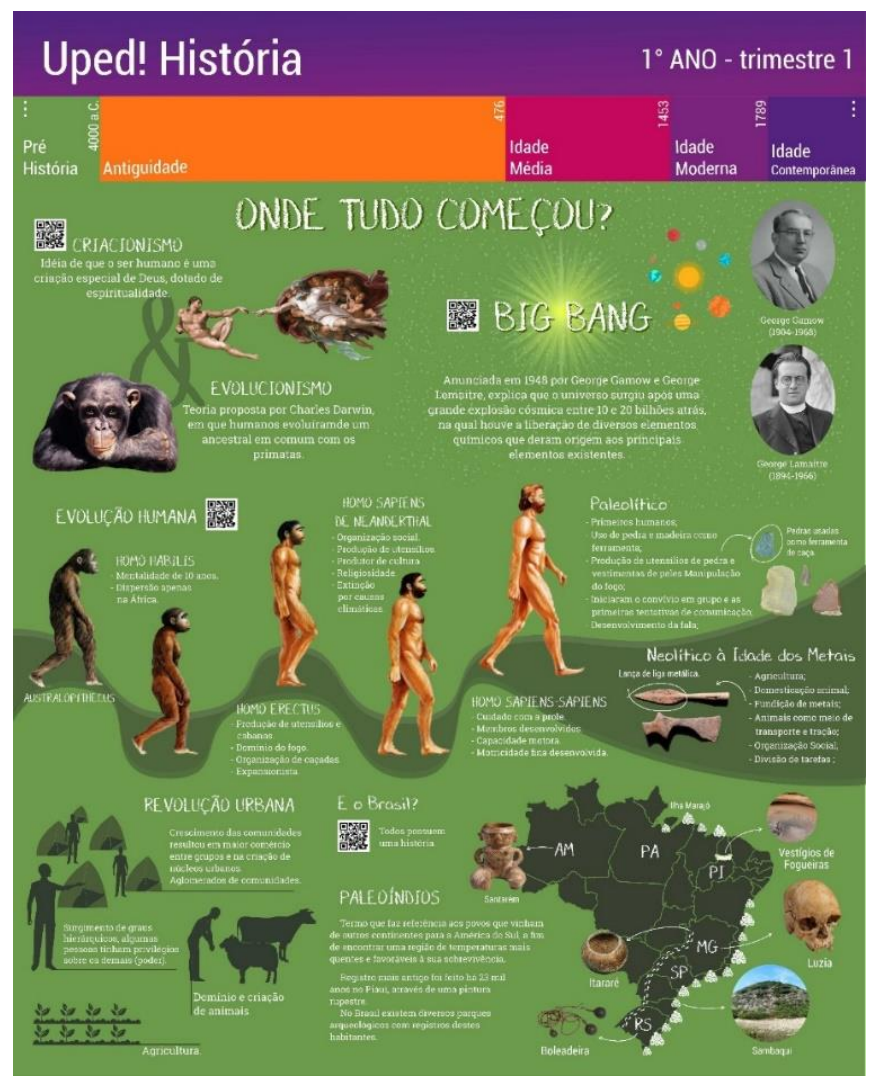

O banner Pré-História possui 5 sub conteúdos e sua ordem de leitura segue o modelo tradicional, portanto a sequência de assuntos foi distribuída da esquerda para direita.

Textos e imagens selecionadas, foram organizadas entre estes blocos, utilizando um esquema de cores predominantemente verde. Os ícones e figuras foram desenvolvidos com inspiração nos materiais dos conteúdos.

As tipografias utilizadas são da família Roboto, Light e Condensed disponíveis no google fonts, e a conexão com o aplicativo é feita através do QR code. O material foi desenvolvido nos softwares CorelDraw e Photoshop, e a impressão gráfica em banner padrão $100 \times 80 \mathrm{~cm}$ na escala de cores CMYK. 
Coelho, M.A. \& Thomazi, P.T. | Design para a educação: Projeto Uped! História, uma ferramenta de ensino para a disciplina de história no ensino médio da rede pública

Figura 3 - Resultado do Banner pré-história e antiguidade (2018).

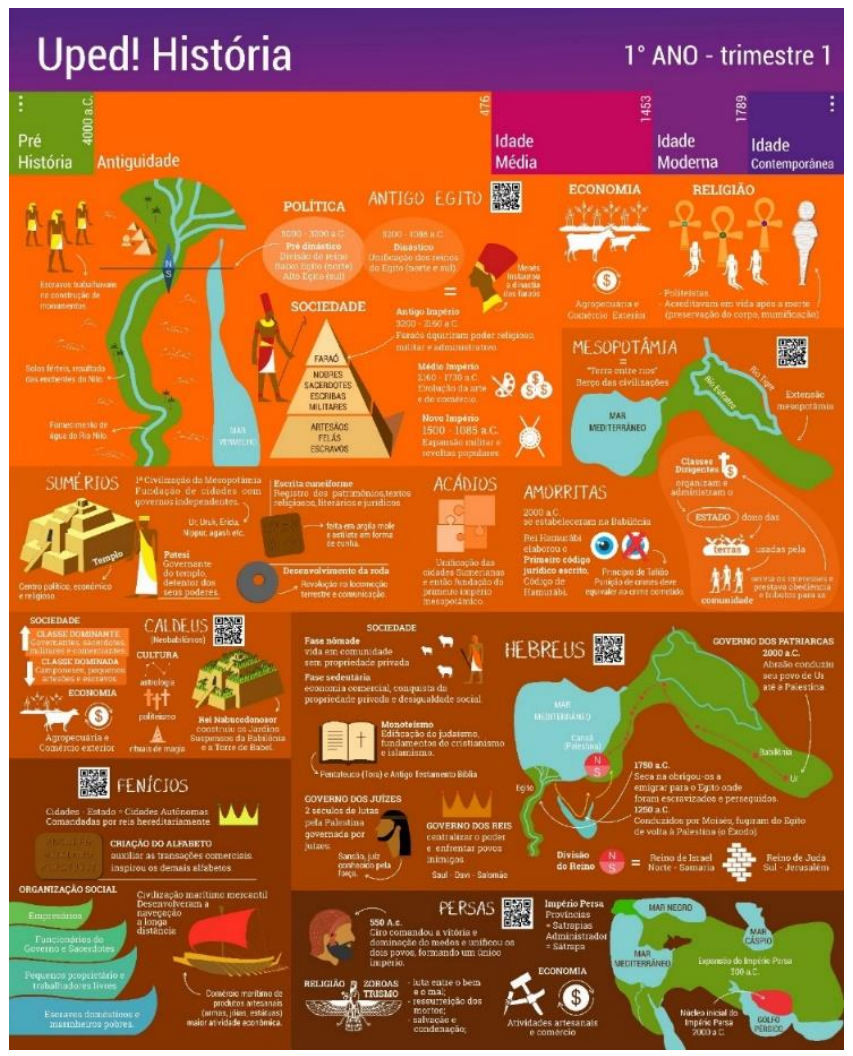

O banner Antiguidade possui 9 sub contéudos, organizados em uma mesma quantidade de blocos, em laranja, seguindo o modelo de leitura tradicional. A distribuição exigiu menos fluidez, para evitar que a leitura seja feita de forma incorreta. As tipografias e a conexão com o aplicativo, e o desenvolvimento foram feitos da mesma forma do banner Pré-História (Figura 2).

O aplicativo foi desenvolvido paralelamente aos banners, mantendo a linguagem dos dois o mais próxima possível. O primeiro contato com o material é feito em sala de aula, onde a professora o introduz em aula e propõe a inclusão do aplicativo como ferramenta de estudo. $O$ aplicativo exige maior interação do que o material impresso, portanto foram pensadas diversas situações de uso, e a melhor forma de oferecer uma ferramenta de estudo sem criar distrações desnecessárias.

Foram analisadas as interações do usuário com o aplicativo, a fim de melhorar a experiência do mesmo, e assim, foi composta a rotulação e mapa de navegação (Figura 4) das ações necessárias para que o aplicativo cumprisse sua função. 
Coelho, M.A. \& Thomazi, P.T. | Design para a educação: Projeto Uped! História, uma ferramenta de ensino para a disciplina de história no ensino médio da rede pública

Figura 4 - Navegação do aplicativo (2018).

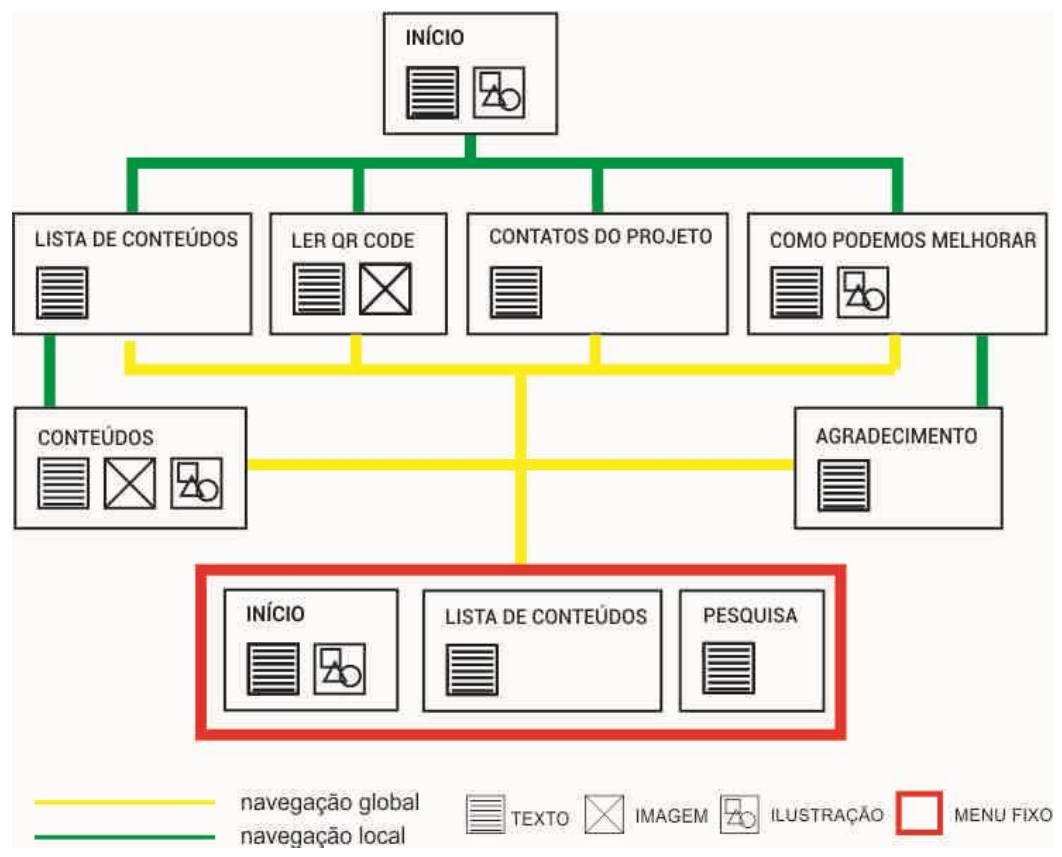

Para controle do usuário sobre o aplicativo, a parte superior possui uma barra fixa, com um menu secundário à esquerda, e a opção de escanear um $Q R$ code à direita. O menu principal do aplicativo exibe todas as ações possíveis de serem realizadas, totalizando 12.

Figura 5 - Tela inicial do aplicativo (2018).
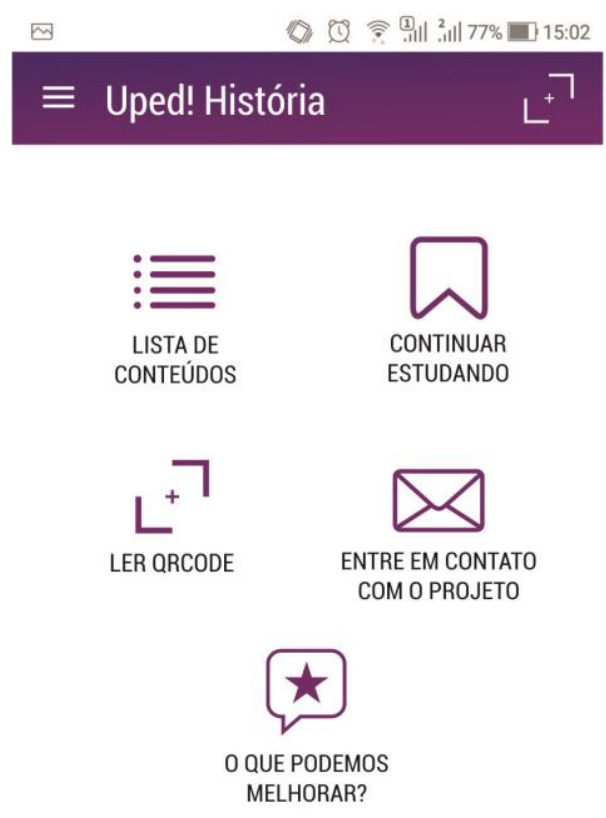

SE QUEREMOS PROGREDIR, NÄOO DEVEMOS REPEIIR A HISTÓRIA,

MAS FAZER UMA HISTÓRA NOVA.

- Mahatma Gandhi - 
A composição das telas foi feita através do grid, segundo a regra de múltiplos de 3 , e a organização do conteúdo foi feita pela transferência das informações dos blocos para a tela com função de rolagem contínua.

A tipografia utilizada permanece a mesma, família roboto, assim como as cores, tendo como resultado a obtenção de materiais que cumprem sua função. A relação professores-banner mais alunos-aplicativos, gera uma troca de experiências que só tem a colaborar com o meio escolar, e proporcionar que a escola amplie o contexto tecnológico.

\section{Considerações finais}

Através desta pesquisa foi possível perceber as dificuldades do ambiente educacional público, porém, a dedicação de muitos professores, e o desejo de crescimento de muitos alunos, possibilita que projetos como esse sejam viáveis.

A sensação de incapacidade dos alunos em relação a aprendizagem é extremamente desmotivante, e causa um desligamento gradual do jovem com a escola. Portanto, fazer a diferença através da inovação da relação deles com o estudo pode mudar o futuro dos mesmos.

A pesquisa e desenvolvimento do projeto, a partir do design com foco na educação, apresentou diversas ferramentas e possibilidades de criação de objetos de estudo voltados para a experiência dos usuários, mas ressalta-se que o projeto foi e deve ser desenvolvido em parceria com um profissional da educação de ensino público, visando garantir a qualidade dos materiais produzidos.

O design da informação e o design instrucional, são campos ainda promissores a serem explorados e utilizados como ferramenta social na construção de uma educação de qualidade. A capacidade do design de mudar a perspectiva das pessoas é a chave para introduzi-lo em ambientes onde muitos dos usuários não percebem a ineficiência dos materiais existentes. Com isso sugerem-se novas pesquisas no ambiente escolar em relação a implementação de materiais gráficos visuais, assim como aplicativos feitos para a sala de aula, que busquem respostas complementares para auxiliar o contexto das escolas públicas. A futura programação do aplicativo e seu teste em sala de aula serão de grande importância para a validação deste projeto.

\section{Referências}

Brasil. Ministério da Educação (MEC). (2006). Secretaria de Educação Fundamental. Departamento de Políticas Educacionais. Coordenação Geral de Educação Infantil. Guia Nacional do Livro Didático. Brasília: MEC/SEF/DPE/COED.

Costa, M. R., Guimarães, E. S., \& Rocha, S. M. O. (2015). Sobre a Infrequência de Alunos no Ensino Médio numa Escola Pública Estadual do Maranhão. Ensino \& Multidisciplinaridade, São Luís, 1(2), pp. 122-137.

Coutinho, S. G., \& Lopes, M. T. (2011). Design para educação: uma possível contribuição para o ensino fundamental brasileiro. In: Braga, Marcos da Costa. (Org.). O Papel social do design gráfico: história, conceitos atuação profissional. São Paulo: Editora SENAC.

Fernandez, Ladreda, R. C. (2004). Infográficos Multimedia: el major ejemplo de notícias hipertextuales. 2004. Disponível em: <www.mediaccion.com>

Filatro, A. (2008). Design Instrucional na Prática. São Paulo: Pearson Education do Brasil, 2008.

Filho, J. G. (2003). Ergonomia do objeto. São Paulo: Escrituras, 2003. 
Coelho, M.A. \& Thomazi, P.T. | Design para a educação: Projeto Uped! História, uma ferramenta de ensino para a disciplina de história no ensino médio da rede pública

Governo Do Estado Do Rio Grande Do Sul. (2016). Secretaria de Estado da Educação (SEDUC). Departamento Pedagógico. Reestruturação Curricular Ensino Fundamental e Médio: Documento Orientador. Porto Alegre.

Horn, R. E. (1998). Visual Language: Global communication for the 21st Century. Washington: Macro VU, 1998.

INEP-MEC. (2018). Ideb: Índice de Desenvolvimento da Educação Básica. Disponível em: <http://portal.inep.gov.br/ideb> Acesso em: 01. nov.

Júnior, J. B. B., Lisboa, E. S., \& Coutinho, C. P. (2011). O infográfico e as suas potencialidades educacionais. In: 4º Encontro Nacional de Hipertexto e Tecnologias Educacionais. Sorocaba.

Krawczyk, N. (2009). Reflexão sobre alguns desafios do ensino médio no Brasil hoje. São Paulo: Ação Educativa.

Martins, B., \& Couto, R. (2008). Design da Informação e a construção de sentido no desenvolvimento de materiais educativos. In: $8^{\circ}$ Congresso Brasileiro de Pesquisa e Desenvolvimento em Design, São Paulo.

Moreira, J. M. (2011). Ensinar História, Hoje. Revista da Faculdade de Letras do Porto, Porto, 2(3), pp. 33-39.

Munari, B. (1981). Das coisas nascem coisas. Lisboa: Edições 70.

Nemi, A. L. L. (2009). Ensino de História e Experiências: O tempo vivido. São Paulo: FTD.

Nielsen, J. (2018). Ten Usability Heuristics. Disponível em: <https://www.nngroup.com/articles/ten-usability-heuristics/> Acesso em: 05 out. 2018.

Qedu. Rio Grande do Sul: Ideb 2017. Disponível em: < https://www.qedu.org.br/ estado/121-riogrande-do-sul/ideb?dependence=2\&grade=3\&edition=2017> Acesso em: 01. Nov. 2018.

Silva, A. S., Cruz, D. A. S., \& Passos, V. M. F. R. (2012). Desıgn De InFormaÇão: Uma Explosão de Possibilidades num Mundo Imagético e Interativo In: II CIDAG Conferência Internacional em Design e Artes Gráficas, Tomar, pp. 1-5.

\section{Sobre os autores}

Maria Alice Coelho, Ulbra, Brasil <coelhosalice@gmail.com>

Patricia Thormann Thomazi, Ulbra, Brasil <pthormann@hotmail.com,

patrícia.thomazi@ulbra.br> 